Scientific Review - Engineering and Environmental Sciences (2021), 30 (1), 208-218

Sci. Rev. Eng. Env. Sci. (2021), 30 (1)

Przegląd Naukowy - Inżynieria i Kształtowanie Środowiska (2021), 30 (1), 208-218

Prz. Nauk. Inż. Kszt. Środ. (2021), 30 (1)

http://iks.pn.sggw.pl

DOI 10.22630/PNIKS.2021.30.1.18

Ezekiel Kaura MAKAMA ${ }^{1,2}$, Hwee San LIM1

${ }^{1}$ Universiti Sains Malaysia, School of Physics

${ }^{2}$ University of Jos, Department of Physics

\title{
Inter-annual and seasonal patterns of precipitable water vapour over Malaysia from 1990-2019 based on MERRA-2 reanalysis
}

Key words: total precipitable water vapour, MERRA-2, monsoon, reanalysis

\section{Introduction}

Total precipitable water vapour $(T P W)$ is the integration of water vapour in a column of atmosphere from the surface of the Earth to space with the potential of being precipitated. $T P W$ is not only the most important greenhouse gas, it is the main source of moisture for precipitation that plays an important feedback role in climate system (Randel et al., 1996). Unlike other greenhouse gases, $T P W$ has high variability both at the spatial and temporal scales, with higher values found equatorward against lower values poleward. The parameter exhibits seasonal patterns, with higher values during summer and lower during winter in the Northern Hemisphere.
Although $T P W$ is influenced by land-sea convection, its value is significantly affected by orography over continental lands since the concentration is mostly within the lower layer of the atmosphere. Its regional variability is also affected by wind circulation like El Nińo-Southern Oscillation (ENSO), which are common signatures in the equatorial belt (Numata et al., 2013).

Knowledge of the spatial and temporal variations of $T P W$ is extremely important in climate models (Ccoica-López, Pasapera-Gonzales \& Jimenez, 2019), the forecast of precipitation, and in the determination of moisture flow over an area (Tuller, 1977). Despite its importance and familiarity to meteorologists, only limited attempts have been made to evaluate the distribution and variability of mean $T P W$ over Malaysia. Most of the published data on $T P W$ values are found only as a minor element in 
dealing with its quantitative forecasting or moisture flow in the area of concern (Peng, Li, Chen, Norizan \& Tay, 2006; Salihin, Musa \& Radzi, 2013; Suparta, Rahman \& Singh, 2014; Suparta and Alhasa, 2016; Makama, Lim \& Abdullah, 2018). Malaysia, being a tropical region with overlapping seasonality and complex orography, is an important area for climate study. Moreover, global and regional phenomena like ENSO also characterize the climate of the region in addition to rising temperature occasioned by global warming. For instance, using twelve coupled Atmospheric-Oceanic General Circulation Models, the Malaysian Meteorological Department projected respective temperature increases of $1.0-3.5^{\circ} \mathrm{C}$ and $1.1-3.6^{\circ} \mathrm{C}$ for East and West Malaysia (Malaysian Meteorological Department [MetMalaysia], 2009). In this study temporal and spatial variations, as well as trend in $T P W$ over Malaysia from 1990 to 2019 are evaluated using the Second Modern-Era Retrospective Analysis for Research and Applications (MERRA-2) data.

\section{Data and methods}

\section{Study area}

Malaysia lies between longitudes $99^{\circ}-120^{\circ} \mathrm{E}$ and latitudes $1^{\circ}-7^{\circ} \mathrm{N}$ in Southeast Asia. The Country consists of three federal territories namely; West Malaysia (or Peninsular Malaysia), Sabah, and Sarawak (jointly called East Malaysia). These two regions, which are separated by the South China Sea, share a largely similar landscape characterized by coastal plains rising to hills and mountains. The climate of Malaysia clas- sified as tropical rainforest and monsoon in which high and constant precipitation is exhibited. Most of the region is made up of maritime continents with different topography. The mountains and the complex land-sea configuration strongly influence both the weather and climate of the Country. The Northeast Monsoon (NEM) and the Southwest Monsoon (SWM) also define the climate of Malaysia.

\section{Datasets}

MERRA-2 reanalysis data from the National Aeronautic and Science Administration (NASA) for the satellite era replaces MERRA reanalysis data using a three-dimensional upgraded version of Goddard Earth Observing System Model (GEOS) with Atmospheric Data Assimilation System (ADAS) ver. 5.12.4. All data products from MERRA-2 are provided at the same resolution of $0.5^{\circ} \times 0.625^{\circ}$ (latitude and longitude), unlike in MERRA. The data was accessed from the website https://nasa. gov/reanalysis/MERRA-2 (last accessed 2 May 2020). In this study, monthly mean $T P W$ data derived from MERRA-2 reanalysis for the period 1990 to 2019 have been used. A collocation box of longitude-latitude grid closest to each of the World Meteorological Organization (WMO) station in the study area was averaged and compared directly with radiosonde $T P W$. Seasonal means were obtained for NEM (November-April) and SWM (May-October) for spatial and temporal patterns (Note: Though two inter-monsoon seasons are also involved in describing the weather of Malaysia, these are not separately considered in the current study). 
Radiosonde data, primarily used to evaluate MERRA-2 product, were freely obtained from Integrated Global Radiosonde Archive (IGRA) ver. 2 of the National Climatic Data Centre (NCDC), available at www.ncdc.noaa.gov (Durre, Vose \& Wuertz, 2008). The requisite $T P W$ data were extracted from twicedaily sounding from WMO stations at Kota Bharu, Penang, Kuantan, and Changi (Singapore), Kota Kinabalu, Tawau, Bintulu, and Kuching for the period 1 January 1990 to 31 December 2019. Quality control was imposed on the daily data to rid it of obvious errors and outliers from the time series of the station data. For homogeneity test, at least 18 daily observations were used to calculate the mean monthly values and 10 valid months were used in deriving the annual mean values of TPW. Data from stations with a consistent time series of 18 years between 1990 and 2019 were considered for the validation of MERRA-2 data. Finally, the daily value was derived as the mean of the night and daytime and then converted into monthly means to conform with those of MERRA-2 for direct comparison.

\section{Trend computation}

Annually averaged monthly mean MERRA-2 precipitable water vapour time series was used to evaluate long-term variability of $T P W$ over each of the three regions in recent decades. Least square regression (LSR) method (Eq. 1) (Zhai \& Eskridge, 1997) was used to detect trend in the MERRA-2 TPW data.

$y(t)=a+b x$ where:

$y$ - total precipitable water vapour $(T P W)$

$[\mathrm{mm}]$,

$a$ - intercept [mm],

$b$ - slope of the line of fit represents the regional water vapour trend $\left[\mathrm{mm} \cdot\right.$ decade $\left.^{-1}\right]$,

$x$-corresponding time [year].

The constants $a$ and $b$ were estimated from (Zhai \& Eskridge, 1997):

$$
\begin{aligned}
& a=\frac{1}{n} \sum y_{i}-\left(\frac{1}{n} \sum x_{i}\right) b \\
& b=\frac{S_{x y}}{S_{x x}}
\end{aligned}
$$

where: $\quad S_{x x}=\sum x_{i}^{2}-\frac{1}{n}\left(\sum x_{i}\right)^{2} \quad$ and $S_{x y}=\left[\sum x_{i} y_{i}-\frac{1}{2}\left(\sum x_{i}\right)\left(\sum y_{i}\right)\right], n$ is the total number of years in the study period while the summation is from $i=1$ to $i=n$. The standard error was obtained from Eq. (4):

$$
\sigma_{b}=\sqrt{\frac{S_{y y}-b S_{x y}}{S_{x x}(n-2)}}
$$

where: $S_{y y}=\sum y_{i}^{2}-\frac{1}{n}\left(\sum y_{i}\right)^{2}$. In this study, the uncertainty of the trend estimate was taken as $S_{y y}=\sum y_{i}^{2}-\frac{1}{n}\left(\sum y_{i}\right)^{2}$ at the $95 \%$ interval. The significance of the trend was determined by the Student's t-test with the following hypotheses: $H_{0}$ : $b=0$ and $H_{1}: b \neq 0$, in which the null 
hypothesis avers that no trend while the alternative hypothesis holds existence of trend. The test statistic was obtained from Eq. (5):

$$
Z=\frac{|b| \sqrt{S_{x x}}}{\sqrt{\frac{S_{y y}-b S_{x y}}{n-2}}}
$$

with the acceptance region for the null hypothesis being $-t_{\alpha} / 2<Z<t_{\alpha} / 2$, where $\alpha$ is the significance level (0.05). If $Z$ is non-zero, the null hypothesis is rejected in favour of the alternative hypothesis, and therefore, enough to say trend exist.

\section{Results and discussion}

\section{Temporal variation of TPW}

To discern mean $T P W$ across Malaysia, eight radiosonde stations were adopted as sub-regional representatives
(Fig. 1). These locations are WMO stations that have long-term homogenous radiosonde data. The in-situ data from these stations were used to validate $T P W$ from MERRA-2 for climatological application in Malaysia. The two sets of data agree well in the study area, with a correlation coefficient of range 0.88 -0.92 and root mean squared error of between 2.05 and $2.61 \mathrm{~mm}$ across the different regions (not shown). Figure 1 is a map of the study area, showing regional locations as well as seasonal fluctuations of $T P W$ in each of the sub-regions represented by radiosonde stations, marked as filled circles.

From Figure 1, double oscillations are seen throughout the stations, with the first and second depressions in February and August. This period is characterized by the lowest amount of rainfall in West Malaysia (Wong, Venneker, Uhlenbrook, Jamil \& Zhou, 2009). Corresponding

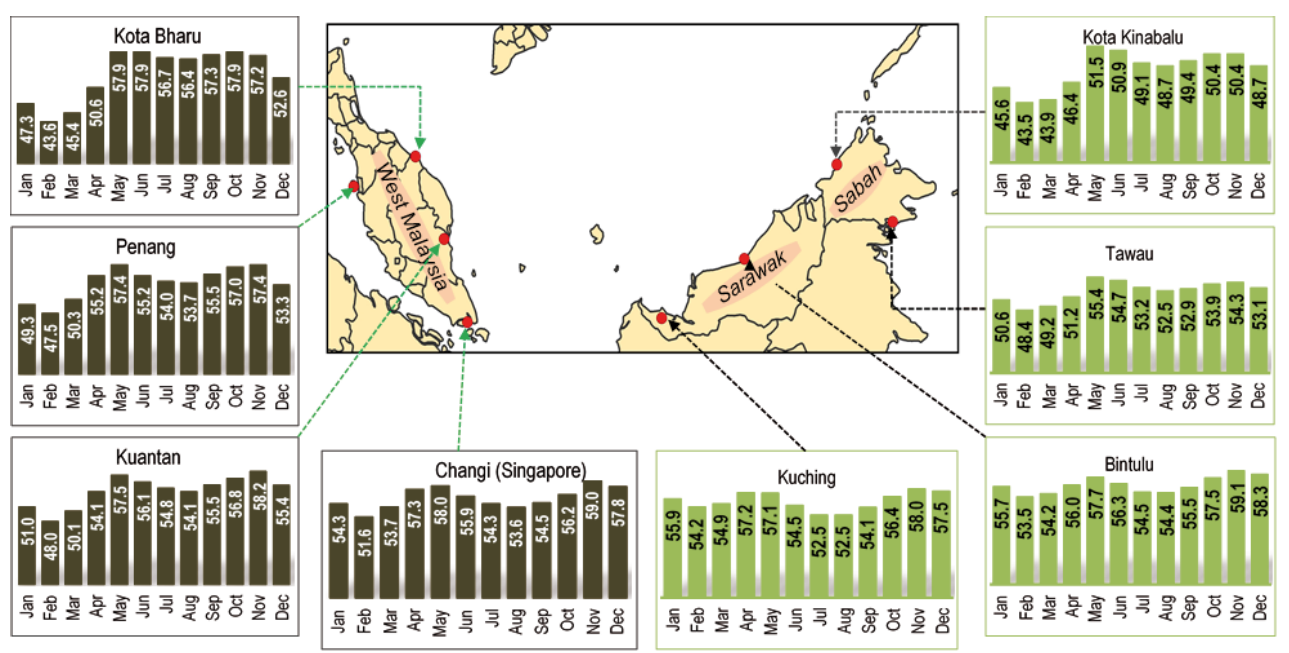

FIGURE 1. Monthly mean total precipitable water vapour (TPW, mm) for representative locations of West Malaysia and East Malaysia (Sabah and Sarawak) from MERRA-2 data from 1990-2019. Inset is the study area showing subregions and the World Meteorological Organization radiosonde stations in filled circles 
peaks are obtained in May and November, which also fall within peak periods of precipitation in the region (Wong et al., 2009). Decreasing $T P W$ is noticed northward in West Malaysia, with the northernmost station, Kota Bharu, presenting lowest mean moisture compared to the three others. Whereas this station provides the least amount of $T P W$ between November and April (NEM season) in West Malaysia, the value is largest between May and October (SWM season). The high amount of $T P W$ observed in the northern part during this period, is most probably due to moisture sheltering effect by high mountain ranges on the SWM winds, which arrive West Malaysia from Sumatra (Wong et al., 2009). The widening of the strait of Malacca northwards may also induce the land-sea breeze and convection that may exert local influence on precipitation in the region during the SWM season (Oki $\&$ Musiake, 1994). Additionally, higher temperature in the northern parts of West Malaysia during this period could induce evaporation rate and consequently produce more moisture content aloft. For instance, MetMalaysia (2009) projected higher mean temperature increases for West Malaysia against lower values for East Malaysia. Changi, which is in the southmost tip of West Malaysia displays reversed mean $T P W$ compared to Kota Bharu with higher and relatively lower values obtained in NEM and SWM respectively. Similarly, synchronous double oscillations were obtained in East Malaysia, though the pairs of dips and peaks are not as conspicuous compared to those observed in West Malaysia. However, unlike the northmost station in West Malaysia, the corresponding sta- tion (Kota Kinabalu) in East Malaysia maintained a consistently lowest amount of $T P W$ all year round, just as the value in the southmost station (Kuching) dominated throughout.

Plots of the annual means of $T P W$ for the three federated regions (Peninsular Malaysia, Sabah, Sarawak) from 1990 to 2019 are depicted in Figure 2a. Sarawak maintains a consistently higher $T P W$ compared to West Malaysia and Sabah. Consistent temporal variation in annual mean $T P W$ was, however, recorded for all the regions. This is consistent with the projected temperature and precipitation trends for the study area (MetMalaysia, 2009). Some obvious spikes noticed in the temporal regime of the annual mean $T P W$ may be linked to ENSO (El Nińo ${ }^{1}$ and La Nińa ${ }^{2}$ ), a common event in the study area and surroundings. This impact is further observed in the monthly anomaly of annual time series in the subsequent section.

To reveal seasonal variability of $T P W$, standard deviations are calculated and depicted in Figure 2b, from which larger deviations were predominantly found during the NEM period in all the stations except for Kuching in East Malaysia. Kota Bharu and Kota Kinabalu presented respective highest deviations in West and East Malaysia, with corresponding least deviations in Changi and Kuching. The regional deviation during

${ }^{1}$ El Nińo is a large-scale ocean-atmosphere climate interaction associated with the episodic warming in sea surface temperatures across the central and east-central Equatorial Pacific, which often results in warm and dry conditions.

${ }^{2}$ La Nińa episodes represent periods of below-average sea surface temperatures across the east-central Equatorial Pacific. 

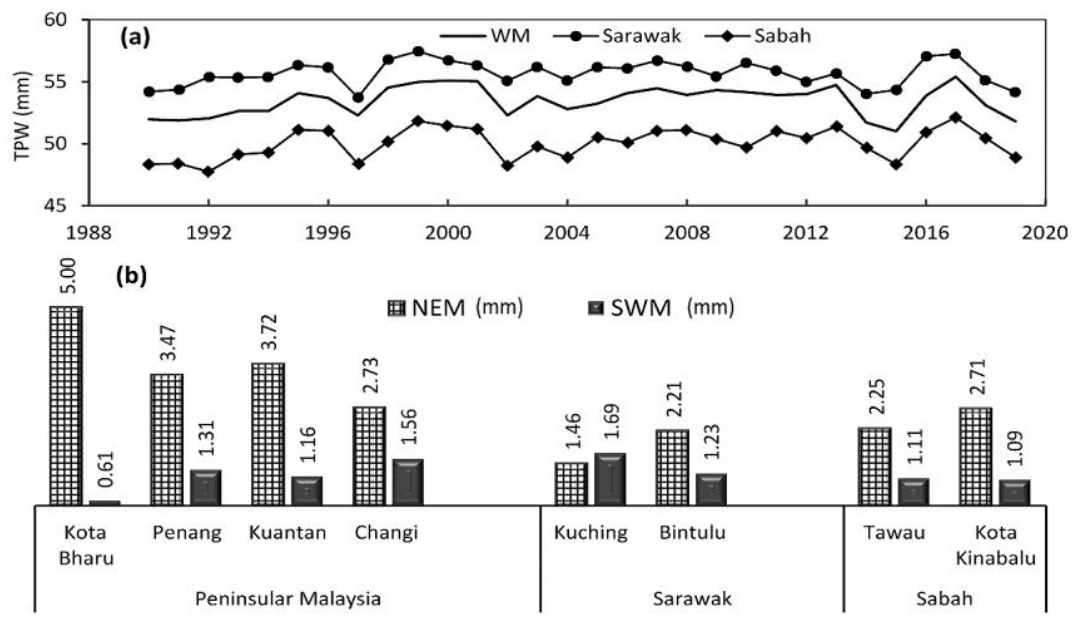

FIGURE 2. Total precipitable water vapour $(T P W)$ from MERRA-2 for the period 1990-2019 for the three sub-regions: a - temporal fluctuation of annual means (WM - West Malaysia); b - standard deviations of seasonal means (NEM - northeast monsoon, SWM - southwest monsoon)

the NEM season is latitude-dependent, with the value falling from $5.00 \mathrm{~mm}$ at Kota Bharu to $2.73 \mathrm{~mm}$ at Changi in West Malaysia and from $2.71 \mathrm{~mm}$ at Kota Kinabalu to $1.46 \mathrm{~mm}$ at Kuching in East Malaysia. Similarly, during the SWM the deviation also trails a latitudinal pattern but with higher increases at lower latitudes. The largest deviations during this period were found in Changi (1.56 mm) and Kuching (1.69 mm), with Kota Bharu presenting the least value $(0.61 \mathrm{~mm})$ across all regions. The relatively small deviations $(0.61-5.00 \mathrm{~mm})$ obtained are to be expected since mean $T P W$ ranges between 44 and $58 \mathrm{~mm}$ in both seasons across Malaysia. The mean seasonal deviations in the NEM (3.07 $\mathrm{mm})$ and SWM (1.22 $\mathrm{mm})$ across the study area are consistent with reported values of $<5 \mathrm{~mm}$ for global equatorial regions (Chen \& Liu, 2016).

\section{Spatial patterns of TPW}

The mean seasonal distribution of $T P W$ and its inter-annual variability for NEM and SWM is depicted in Figure $3 \mathrm{a}$ and $b$. From the left column of the figure, which presents maps of the means, it is observed that $T P W$ decreases generally in a southeast-northwest orientation over Peninsular Malaysia, with regional maximum appearing over the southeastern tip of the area in both seasonal distribution of the means. The distribution over East Malaysia is, however, in a southwest-northeast orientation with regional maximum found in the southwestern area. The spread of $T P W$ over Malaysia is dominated by latitude, topographical features, and the monsoons. The isopleths of TPW closely match the orographic features of Malaysia and reflect the influence of the monsoons. The atmospheric column is much shorter over 
the central area of West Malaysia, the eastern part of Sarawak, and northwestern Sabah due to their high elevation, which explains the observed regional $T P W$ minima. Although the elevation is lower in the northwestern part of West Malaysia, $T P W$ values are relatively low due to the weakened influence of the SWM from the natural barrier formed by the mountains to the south. Complex and steep orography tends to shape intense horizontal gradient along the edges of West Malaysia and along the central and northeastern parts of East Malaysia. The rich horizontal gradients that manifest along the central regions of Sarawak and the entire Sabah are relatively uniform in the two seasons. Weak gradients are easily noticed over the southern and central parts of Peninsular Malaysia and west of Sarawak. More water vapour is accounted for during the SWM than in the NEM throughout Malaysia, which is consistent with the seasonal cycle shown in Figure 1. From the right column of Figure 3 (inter-annual variability of $T P W$ in the two season) it is noted that larger variations found during the NEM season have higher values northwards. The variation in the SWM period has much lower amplitude which decreases with latitude. The spatial distributions of the mean and standard deviations of TPW are consistent with its temporal pattern discussed earlier in this work.

\section{Long-term variability of TPW}

For a better understanding of climate dynamics, it is important to investigate long-term trend in precipitable water vapour over a region (Durre, Williams, Yin $\&$ Vose, 2009). Linear trends between 1990 and 2019 in monthly anomalies from MERRA-2 TPW have, therefore, been performed for each region using LSR method. The statistical significance
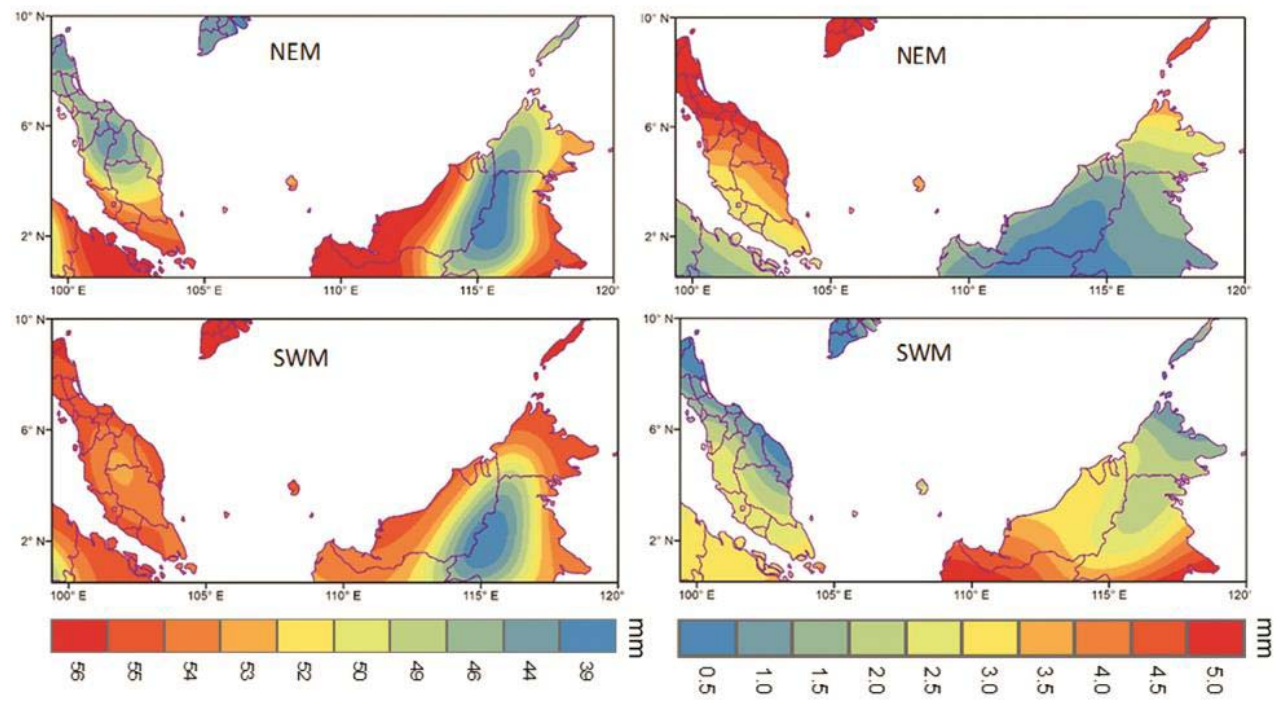

FIGURE 3. Mean total precipitable water vapour (TPW) from MERRA-2 in season 1990-2019: $\mathrm{a}$ - for northeast monsoon (NEM); b - for southwest monsoon (SWM); $\mathrm{c}$-standard deviation of NEM; $\mathrm{d}-$ standard deviation of SWM 
of the trends, the slope, and the probability ( $p$-value) along with the trend direction for the annual time scales are presented in the table. Trends of TPW estimated from MERRA-2 over the regions are positive but very low, though the values are statistically significant at the $95 \%$ level, except for Sarawak. The $Z$-scores are consistent with the $p$-values within the study period. Statistically significant upward trends of the rate $0.09 \pm 0.06 \mathrm{~mm} \cdot$ decate $^{-1}$ and $0.10 \pm 0.04$ $\mathrm{mm} \cdot$ decate $^{-1}$ were obtained in West Malaysia and Sabah respectively. However, Sarawak turned in nonsignificant positive trend rate of $0.05 \pm 0.01 \mathrm{~mm} \cdot$ decate $^{-1}$. The results are consistent with the very low upward trend obtained for the tropics (Chen \& Liu, 2016; Parracho, Bock $\&$ Bastin, 2018). Moreover, this positive trend is consistent with reported temperature increases in Malaysia (MetMalaysia, 2009).
2016. Records from the Oceanic Nińo Index (ONI) indicate the occurrence of very strong El Nińo events within $1997 / 1998$ and 2015/2016, with corresponding moderate/strong La Nińa from 1998-2000 and also 2017 (https://origin. cpc.ncep.noaa.gov). These events, which are partly responsible for the drying and moistening of water vapour contents in the atmosphere around the South $\mathrm{Pa}$ cific, are most likely to affect the trend in $T P W$. The high anomalies observed in 1998-2000 and 2017 are most likely due to La Nińa, while the troughs from 1997 to 1998 and from 2015 to 2016 may be attributed to El Nińo. Although most of these events may result in drier or wetter years, substantial frequency of relatively dry or wet periods in Malaysia are, however, not accounted for by them. This indicates that ENSO may not be solely responsible in regulating moisture amount in the study area.

TABLE. Decadal trend estimates in MERRA-2 total precipitable water vapour $(T P W)$ over the three federated regions of Peninsular Malaysia for the annual time scale (b) from 1990-2019. Z-scores, $p$-values and trend directions are also given

\begin{tabular}{|l|c|c|c|c|}
\hline Region & $Z$ & $\begin{array}{c}b \\
{\left[\mathrm{~mm} \cdot \mathrm{decade}^{-1}\right]}\end{array}$ & $\begin{array}{c}p \\
\left(\alpha_{0.05}\right)\end{array}$ & $\begin{array}{c}\text { Trend } \\
\text { (at 95\% significant level) }\end{array}$ \\
\hline West Malaysia & 2.17 & $0.09 \pm 0.06$ & 0.014 & positive \\
\hline Sarawak & $1.48^{*}$ & $0.05 \pm 0.01$ & 0.086 & positive \\
\hline Sabah & 2.61 & $0.10 \pm 0.03$ & 0.009 & positive \\
\hline
\end{tabular}

*Non-significant trend.

The domain means of monthly anomalies in annual time series from MERRA-2 TPW for the box area over each of the three federated regions in Malaysia is given in Figure 4. The figure depicts some curious sharp rises and falls in the annual anomaly of $T P W$ particularly, from 1995 to 2000 and 2015 to

\section{Conclusions}

The implication of total precipitable water vapour $(T P W)$ variability and trend on the Earth's radiation budget and precipitation calls for its regular and regional monitoring. This study evaluates the inter-annual and seasonal patterns 


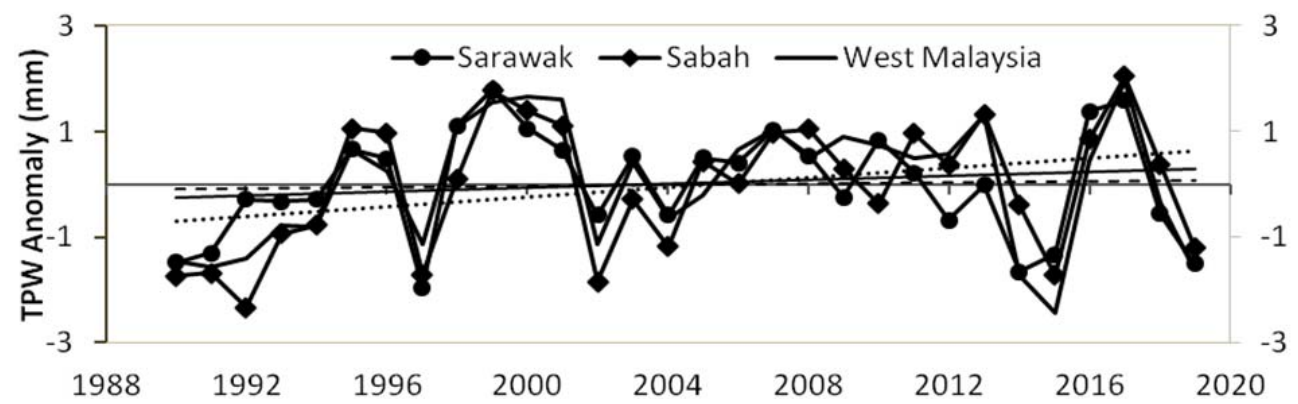

FIGURE 4. Domain mean of monthly anomalies in annual time series from MERRA-2 total precipitable water vapour $(T P W)$ for the box areas of Sarawak, Sabah, and West Malaysia from 1990-2019

of $T P W$ over Malaysia based on a 30-year data from the Second Modern-Era Retrospective analysis for Research and Applications (MERRA-2). Bimodal oscillations of $T P W$ were discernible at the seasonal time scale, with a pair of maxima found in May and November, coinciding with the respective starts of the NEM and SWM seasons in Malaysia. Corresponding pair of minima, which occurred in February and August, are more conspicuous in West Malaysia. The spatial patterns of the annual mean $T P W$ were also characterized by a pair of high and low with marked geographical differences as complex and steep orography shaped intense horizontal gradient along the edges of West Malaysia, western part of Sarawak, and southeastern area of Sabah. More moisture was found during the SWM period in all the regions, with higher values in the western part of the Country. Kota Kinabalu and Tawau, in the northeastern part of East Malaysia were the driest all year round. Generally, $T P W$ was observed to decrease northward with slight upward significant trends of approx. $0.09 \mathrm{~mm} \cdot$ decade $^{-1}$ at the $95 \%$ level, found in West Malaysia for the annual time scale, which is consistent with reported global tropical positive trend (Chen \& Liu, 2016). Trend of $T P W$ within the study period is most likely affected by ENSO, which is a common events in Malaysia and surrounding areas. It is, therefore, suggestive to isolate periods of severe ESNO events in order to decern actual decadal variability in $T P W$ over the study area.

\section{Acknowledgement}

This research was funded by RUI grant (Burning in Southeast Asia Maritime Continent), 1001/PFIZIK/8011079. Authors are grateful to the National Aeronautics and Space Administration (NASA) for providing MERRA-2 data (https://nasa.gov/reanalysis/MERRA2/data_access) and the National Oceanic and Atmospheric Administration (NOAA) for the IGRA2 data (www. ncdc.noaa.gov/data-access/weather-balloon/integrated-global-radiosonde-archive).

\section{References}

Ccoica-López, K., Pasapera-Gonzales, J. \& Jimenez, J. (2019). Spatio-temporal variability of the precipitable water vapor over Peru through MODIS and ERA-Interim time 
series. Atmosphere, 10(4), 192. https://doi. org/10.3390/atmos 10040192

Chen, B. \& Liu, Z. (2016). Global water vapor variability and trend from the latest 36 year (1979 to 2014) data of ECMWF and NCEP reanalyses, radiosonde, GPS, and microwave satellite. Journal of Geophysical Research: Atmospheres, 121(19), 11442-11462. https:// doi.org/10.1002/2016JD024917

Durre, I., Vose, R.S. \& Wuertz, D.B. (2008). Robust Automated Quality Assurance of Radiosonde Temperatures. Journal of Applied Meteorology and Climatology, 47(8), 2081-2095. https://doi.org/10.1175/2008JAMC1809.1

Durre, I., Williams, C.N., Yin, X. \& Vose, R.S. (2009). Radiosonde-based trends in precipitable water over the Northern Hemisphere: An update. Journal of Geophysical Research Atmospheres, 114(5), 1-8. https://doi. org/10.1029/2008JD010989

Makama, E.K., Lim, H.S. \& Abdullah, K. (2018). Parameterization of the middle and upper tropospheric water vapor from ATOVS observations over a tropical climate region. Journal of Atmospheric and Solar-Terrestrial Physics, 167, 190-199. https://doi. org/10.1016/j.jastp.2017.12.005

Malaysian Meteorological Department [MetMalaysia] (2009). Climate change scenarios for Malaysia 2001-2099. Petaling Jaya: Malaysian Meteorological Department.

Numata, S., Yasuda, M., Suzuki, R.O., Hosaka, T., Noor, N.S.M., Fletcher, C.D. \& Hashim, M. (2013). Geographical pattern and environmental correlates of regional-scale general flowering in peninsular Malaysia. PLOS ONE, 8(11), e79095. https://doi.org/10.1371/ journal.pone.0079095

Oki, T. \& Musiake, K. (1994). Seasonal Change of the Diurnal Cycle of Precipitation over Japan and Malaysia. Journal of Applied Meteorology, 33(12), 1445-1463. https://doi. org/10.1175/1520-0450(1994)033<1445: SCOTDC $>2.0 . \mathrm{CO} ; 2$

Parracho, A.C., Bock, O. \& Bastin, S. (2018). Global IWV trends and variability in atmospheric reanalyses and GPS observations. Atmospheric Chemistry and Physics, 18(22), 16213-16237. https://doi.org/10.5194/acp18-16213-2018
Peng, G., Li, J., Chen, Y., Norizan, A.P. \& Tay, L. (2006). High-resolution surface relative humidity computation using MODIS image in Peninsular Malaysia. Chinese Geographical Science, 16(3), 260-264. https://doi. org/10.1007/s11769-006-0260-6

Randel, D.L., Harr, T.H.V., Ringerud, M.A., Stephens, G.L., Greenwald, T.J. \& Combs, C.L. (1996). A new Global Water Vapor dataset. Bulletin of the American Meteorological Society, 77(6), 1233-1246.

Salihin, S., Musa, T.A. \& Radzi, Z.M. (2013). Spatio-temporal estimation of integrated water vapour over the Malaysian peninsula during monsoon season. International Archives of the Photogrammetry, Remote Sensing and Spatial Information Sciences - ISPRS Archives, 42(4W5), 165-175. https://doi. org/10.5194/isprs-archives-XLII-4-W5-1652017

Suparta, W. \& Alhasa, K.M. (2016). Modeling of Precipitable Water Vapor Using an Adaptive Neuro-Fuzzy Inference System in the Absence of the GPS Network. American Meteorological Society, 55, 2283-2300. https://doi.org/10.1175/JAMC-D-15-0161.1

Suparta, W., Rahman, R. \& Singh, M.S.J. (2014). Monitoring the variability of precipitable water vapor over the Klang Valley, Malaysia during flash flood. IOP Conference Series: Earth and Environmental Science, 20(1), 012057. https://doi.org/10.1088/1755$1315 / 20 / 1 / 012057$

Tuller, S.E. (1977). The relationship between precipitable water vapor and surface humidity in New Zealand. Archiv Für Meteorologie, Geophysik Und Bioklimatologie. Serie A, 26(2-3), 197-212. https://doi.org/10.1007/ BF02247163

Wong, C.L., Venneker, R., Uhlenbrook, S., Jamil, A.B.M. \& Zhou, Y. (2009). Variability of rainfall in Peninsular Malaysia. Hydrology and Earth System Sciences Discussions, 6(4), 5471-5503. https://doi.org/10.5194/hessd-65471-2009

Zhai, P. \& Eskridge, R.E. (1997). Atmospheric Water Vapor over China. Journal of Climate, 10(10), 2643-2652. https://doi. org/10.1175/1520-0442(1997)010<2643: AWVOC $>2.0 . \mathrm{CO} ; 2$ 


\section{Summary}

Inter-annual and seasonal patterns of precipitable water vapour over Malaysia from 1990-2019 based on MERRA-2 reanalysis. In this study seasonal and inter-annual patterns as well as trend in the total precipitable water vapour $(T P W)$ over Malaysia, based on a 30-year data from MERRA-2, have been evaluated using least square regression method. Indicator $T P W$ revealed a pair of minima in February/August and maxima in May/November with highest and lowest long-term means found in East Malaysia. Long-term seasonal variability of $T P W$ exhibited latitudinal dependency in both the NEM and SWM seasons. Indicator $T P W$ showed respective southeast-northwest and southwest-northeast spatial distribution in West and East Malaysia, with the highest statistically significant positive trend found in the former.

\section{Authors' address:}

Ezekiel Kaura Makama

(https://orcid.org/0000-0001-7074-0037)

University of Jos

Department of Physics

PMB 2084, Jos

Nigeria

Universiti Sains Malaysia

School of Physics

11800 USM, Pulau Pinang

Malaysia

e-mail:makamae@unijos.edu.ng

Hwee San Lim - corresponding author (https://orcid.org/0000-0002-4835-8015)

Universiti Sains Malaysia

School of Physics

11800 USM, Pulau Pinang

Malaysia

e-mail: hslim@usm.my; makama@usm.my 